\title{
Rare non-syndromic intellectual disability
}

INSERM

\section{Source}

INSERM. (1999). Orphanet: an online rare disease and orphan drug data base. Rare nonsyndromic intellectual disability. ORPHA:101685

Rare non-syndromic intellectual disability is a rare, hereditary, neurologic disease characterized by early-onset cog nitive impairment as a sole disability. The disease may be associated with autism, epilepsy and neuromuscular deficits. 